\title{
Prevalence of primary headaches in Germany: results of the German Headache Consortium Study
}

\author{
M-S Yoon - Z. Katsarava $\cdot$ M. Obermann - G. Fritsche • \\ M. Oezyurt · K. Kaesewinkel · A. Katsarova • \\ I. Santowski $\cdot$ H. Diener $\cdot$ S. Moebus
}

Received: 28 December 2011/ Accepted: 10 February 2012/Published online: 7 March 2012

(C) The Author(s) 2012. This article is published with open access at Springerlink.com

\begin{abstract}
We investigated the prevalence of migraine (MIG), tension-type headache (TTH), and chronic headache in a population-based sample in Germany. A total of 18,000 subjects aged between 18 and 65 years were screened from 2003 until 2005 using a validated questionnaire. Overall 9,944 participants $(55.2 \%)$ responded (mean age $43 \pm$ 13.1 years, $52.7 \%$ women). Headache frequency $<15$ days/ month was reported by $5,350(55.5 \%)$ subjects of whom 1,601 (16.6\%, [95\% confidence interval (95\% CI): $15.9-$ 17.4]) reported episodic MIG, $1,202(12.5 \%, 95 \%$ CI 11.8-13.1) episodic TTH, and 1,150 (11.9\%, [11.3-12.6]) episodic MIG + episodic TTH, 1,396 (14.5\%, [13.8-15.2]) unclassifiable headache. In women, episodic MIG peaked between 36 and 40 years, episodic MIG + TTH between 18 and 35 years and episodic TTH between 56 and 66 years. In men, episodic MIG was predominant between 36 and 45 years, episodic MIG + TTH between 26 and 35 years and episodic TTH showed comparable frequency between 36 and 66 years. Headache $\geq 15$ days/month was reported by $2.6 \%(n=255$, [95\% CI 2.3-3]). Chronic MIG was reported by $1.1 \%$ ( $n=108,[0.91-1.33])$, chronic TTH $(n=50$, [95\% CI 0.4-0.7]), chronic MIG + TTH $0.8 \%$
\end{abstract}

\footnotetext{
M.-S. Yoon $(\square)$

Department of Neurology, Ruhr-University Bochum, Gudrunstr. 56, 44791 Bochum, Germany

e-mail: Min-Suk.Yoon@uni-due.de

M.-S. Yoon - Z. Katsarava - M. Obermann - G. Fritsche .

M. Oezyurt · I. Santowski · H. Diener

Department of Neurology and Headache Center, University

Duisburg-Essen, Hufelandstr. 55, 45147 Essen, Germany

K. Kaesewinkel · A. Katsarova · S. Moebus

Institute for Medical Informatics, Biometry and Epidemiology,

University Duisburg-Essen, Hufelandstr. 55,

45122 Essen, Germany
}

( $n=74,95 \%$ CI $0.6-0.9)$ and unclassifiable headache $0.2 \%$ $(n=23$, [95\% CI 0.1-0.3]). Chronic headache was more frequent in women compared to men with the highest prevalence between 46 and 65 years. It is of note that the number of subjects with chronic headache is small in all age groups. The results of our large, population-based study provide reliable, age- and sex-specific estimates of the prevalence of primary headache disorders in Germany. The prevalence with respect to episodic and chronic primary headache disorders in Germany is comparable to other European countries and the USA.

Keywords Migraine - Tension-type headache . Chronic daily headache $\cdot$ Prevalence

\section{Introduction}

The two most common primary headache disorders, migraine (MIG) and tension-type headache (TTH), affect up to $80 \%$ of the general population worldwide [1]. Both disorders are classified by the International Headache Society (IHS) into two different categories depending on headache frequency: episodic ( $<15$ headache days per month) and chronic ( $\geq 15$ headache days per month) [2]. Chronic daily headache [including both, chronic migraine (cMIG) and chronic TTH (cTTH)] is quite common and affects approximately $3-4 \%$ of the general population [3-5]. In particular, cMIG is associated with a significant burden of illness for individuals, their families and the society $[6,7]$. However, comprehensive data of the prevalence in the general population with respect to age and sex are rare. The German Headache Consortium Study (GHC) is an ongoing population-based, longitudinal cohort study designed to investigate the prevalence and incidence of primary 
headache disorders in the general population of Germany. Here, we present detailed baseline data on the prevalence of MIG, TTH and chronic headache by age and sex.

\section{Methods}

Study design and study population

Baseline data of the GHC were assessed between 2003 and 2005. The study was approved by the ethics committee of the University of Duisburg-Essen, Germany. Informed written consent was obtained via postal mail from all subjects. Subjects were randomly selected from statutory lists of residence drawn from three regions in Germany: the city of Essen, a large town $(585,481$ residents) in the region of North Rhine-Westphalia in the western part of Germany; the city of Muenster, a medium-sized town $(272,890$ residents), also in the western part of Germany; and Sigmaringen, a rural area, consisting of a small town with 16,501 inhabitants and 20 surrounding villages in southern Germany. Inclusion criteria were: (i) age between 18 and 65 years, and (ii) German citizenship, to ensure proper knowledge of the German language in order to properly fill out the questionnaire.

Figure 1 illustrates the flow chart of the screening procedure. Eighteen thousand randomly selected subjects received a questionnaire via postal mail (Fig. 1). Subjects who did not respond $(44.8 \%)$ were called for at least eight times for an interview by telephone. Interviews were performed by trained medical students using the same questionnaire. Main reasons for non-response by phone were that subjects could not be reached $(32.9 \%)$ or refused the interview (8.7\%; Fig. 2). Overall, we obtained information per mailed questionnaire or telephone interview from $n=9,944(55.2 \%)$ participants.

\section{Questionnaire}

The questionnaire was constructed based on the criteria of the IHS [8] and validated prior to the survey in 278 patients. The results of the validation were reported elsewhere $[4,9]$. First, the participants were asked if they experienced any kind of headache in the last year. The questionnaire was designed to collect demographic data, and information regarding MIG, TTH and trigeminal
Fig. 1 Screening procedure. Eighteen thousand randomly selected subjects received a questionnaire via postal mail. Subjects who did not respond were called for at least eight times for an interview by telephone. Main reasons for non-response by phone were that subjects were not available or refused the interview. Overall, we obtained information per mailed questionnaire or telephone interview from $n=9,944$

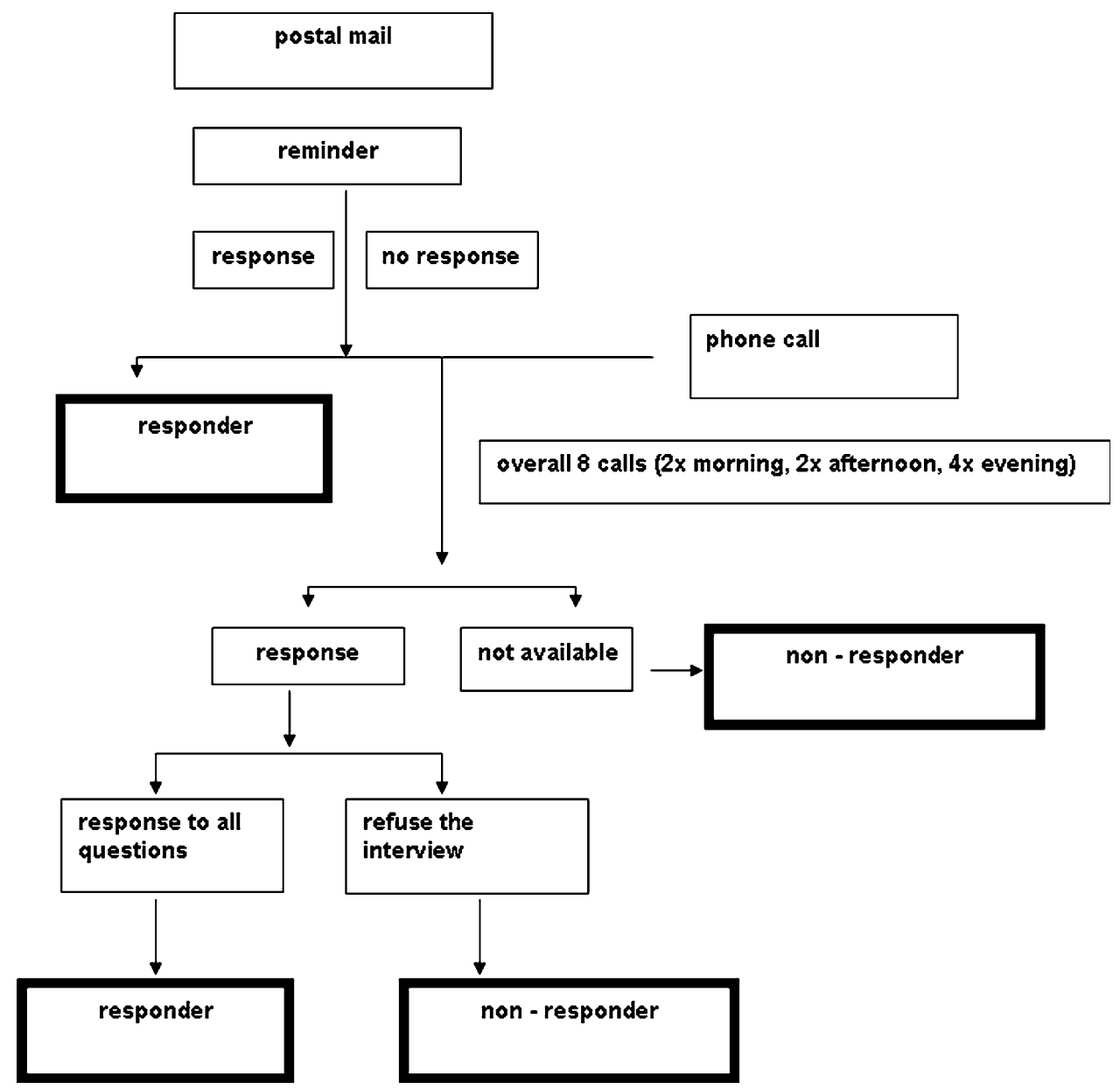




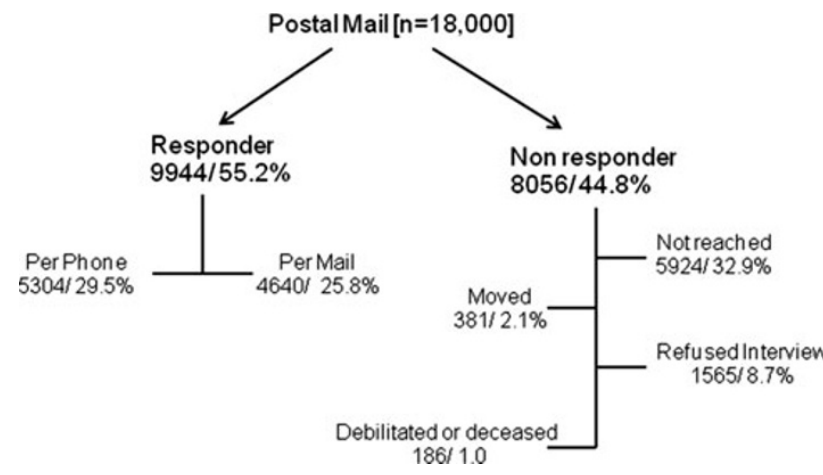

Fig. 2 Responder versus non-responder. Overall 9,944 (55.2\%) individuals responded of whom 4,640 (25.8\%) answered via postal mail, and 5,304 (29.5\%) by telephone. 8,056 (44.8\%) were nonresponder, of whom $1,565(8.7 \%)$ refused the interview, 5,924 $(32.9 \%)$ could not be reached, $381(2.1 \%)$ moved away and 186 $(1.0 \%)$ were debilitated or deceased

autonomic cephalalgias in the last 3 months. Notably, the questionnaire allowed for the diagnosis of each headache type. For example, in a person with more than one headache type, one headache type might be classified as MIG and another as TTH. The questionnaire asked a series of questions that allowed for the diagnosis of migraine and/or TTH according to the definition of the revised version of the international classification of headache disorders (ICHD-II) and the assessment of headache attack frequency per month in migraine and TTH.

The questionnaire did not allow for the diagnosis of each headache attack; this type of data is best ascertained through a daily headache diary.

\section{Diagnostic criteria}

Definitive migraine was diagnosed if all IHS criteria were met, probable MIG if all but one IHS criteria were fulfilled, but the participant did not fulfill the IHS criteria for TTH. Definitive TTH was defined if all IHS criteria were met, probable TTH if all but one IHS criteria for TTH was met, but the participant did not fulfill the IHS criteria for MIG. Chronic daily headache was defined as headache present on $\geq 15$ days/month and not meeting criteria for trigeminal autonomic cephalalgias (TACs). Overlap between MIG and TTH as well as either MIG or TTH and headache on $\geq 15$ days/month was possible because the latter included chronic MIG and chronic TTH. Episodic primary headache disorders, definite MIG and definite TTH as well as probable MIG and probable TTH were summarized as episodic AllMIG (epAll-MIG) and episodic All-TTH (epAll-TTH) [10].

\section{Statistical analysis}

The aim of the current manuscript was to provide detailed information on the prevalence of primary headaches stratified by age and gender. Therefore, all results are provided as percentages in which number of cases is divided by the number of responders who duly completed the questionnaire. Categorical variables were described as percentages with their $95 \%$ confidence intervals $(95 \% \mathrm{CI})$. All analyses were carried out using SPSS, version 14.0 (SPSS Inc., Chicago, IL, USA).

\section{Results}

Overall 9,944 (55.2\%) individuals responded (Fig. 2). Of these 4,640 (25.8\%) answered via postal mail, and 5,304 (29.5\%) by telephone. 8,056 (44.8\%) were non-responder, of whom $1,565(8.7 \%)$ refused the interview, 5,924 (32.9\%) could not be reached, 381 (2.1\%) moved away and 186 (1.0\%) were debilitated or deceased. Non-responder tended to be younger ( $39.8 \pm 12.6$ resp. $43.0 \pm 13.1$ years) and were slightly more often men (men 53.3\%, women $46.7 \%$ ). Information on headache type was missing in $31(0.3 \%)$ questionnaires (Fig. 3). These subjects only answered whether they experienced any kind of headache last year. In $278(2.8 \%)$ cases, data about headache frequency were missing (Fig. 3).

In 9,912 cases, data about headache type were complete. The questionnaire was completed by 9,635 respondents.

All primary headache disorders $(n=9,912)$

Table 1 shows the prevalence of headache disorders separated into episodic and chronic headache conditions stratified by sex and age groups. The prevalence was as follows:

All-MIG 17.9\% ( $n=1,774$; [95\% CI 17.1-18.6]), AllTTH $13.3 \%(n=1,317$; [95\% CI 12.6-13.9]), All-MIG + TTH $12.8 \%$ ( $n=1,272$; [95\% CI 12.2-13.5]), unclassifiable headache $15.3 \% \quad(n=1,520 ; \quad[95 \% \quad$ CI $14.6-16.0])$ (Table 1). In women, All-MIG (23.9\%; [95\% CI 22.8-25.1]) and unclassifiable headache were most frequent $(15.7 \%$; [95\% CI 14.7-16.7]). All-MIG + TTH and All-TTH were quite similar (Table 1). The prevalence among men was as follows: All-MIG 11.1\% $(n=522$; [95\% CI 10.2-12.0]), All-TTH $12.0 \%$ ( $n=561$; [95\% CI 11.0-12.9]), All-MIG + TTH $10.6 \%(n=498$; [95\% CI 9.7-11.5]), unclassifiable headache $14.9 \%$ ( $n=701$; [95\% CI 13.9-15.9]). It is of note that participants with migraine were identified to suffer more from definite migraine than probable migraine (3.1-fold), whereas in tension-type headache and MIG + TTH subjects tend to suffer more probable TTH and probable MIG + TTH (2.7- and 1.5-fold).

Episodic headache $(N=9,635)$

Figure 3 depicts the overall prevalence of headache in 9,635 participants followed by the distribution of headache 
Fig. 3 Prevalence of episodic and chronic primary headache disorders. In total, 9,944 participants responded of whom in 31 cases $(0.3 \%)$ information on headache type was missing. In $278(2.8 \%)$ cases, data about headache frequency were missing. The questionnaire was duly completed by 9,635 respondents. Episodic headache was reported by $55.5 \%$, chronic headache by $2.6 \%$ and no headache by $41.8 \%$ of the participants

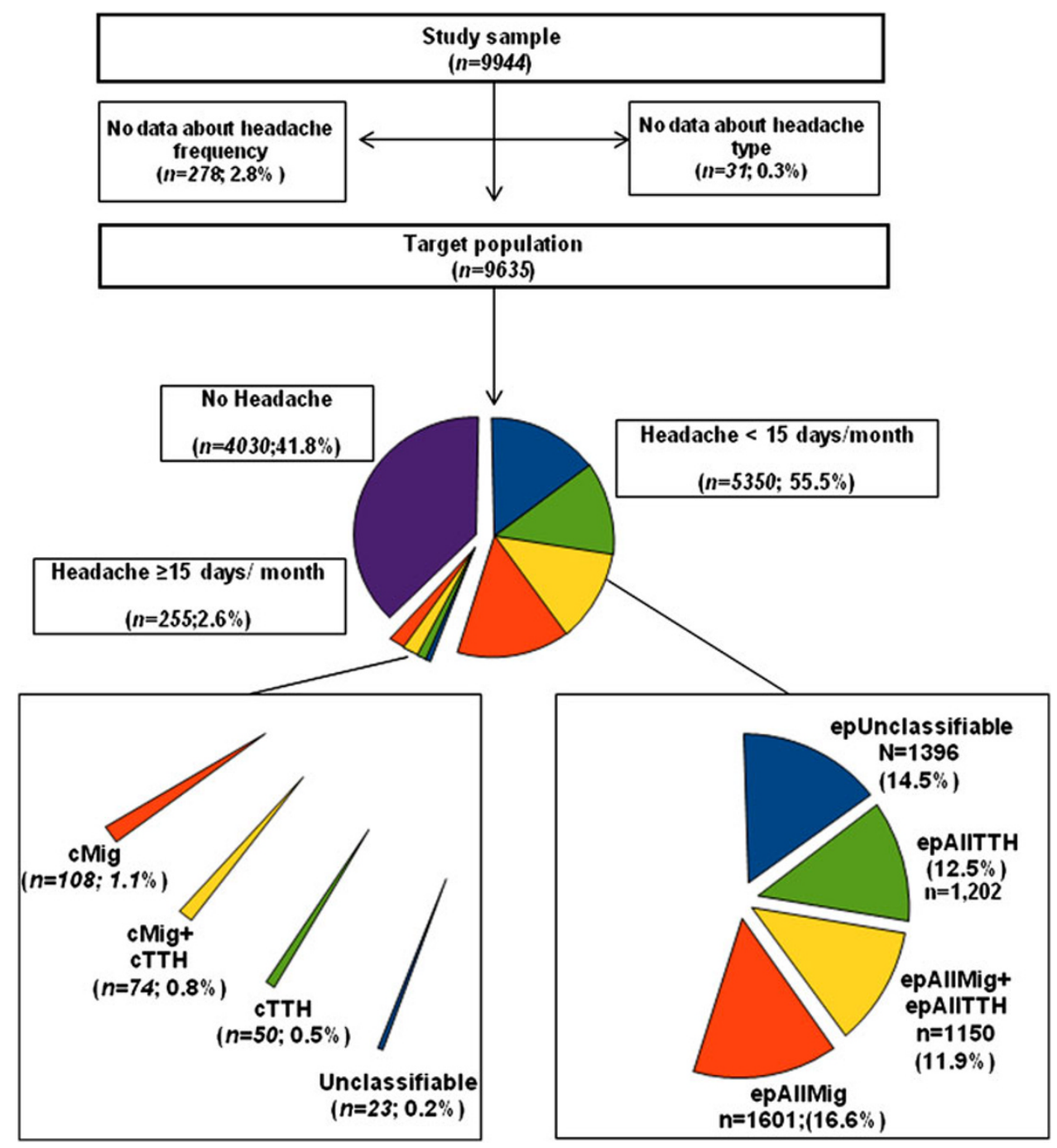

type, out of which $55.5 \%$ reported headache that occurred on less than 15 days per month. Table 2 shows the prevalence of episodic headache types with regards to sex and age group. Of those suffering from headache, episodic AllMIG was the most common reported headache type with $29.9 \%$ ( $n=1,601$; [95\% CI 28.7-31.2]), followed by unclassifiable episodic headache $26.1 \%(n=1,396$; [95\% CI 24.9-27.3]), epAll-TTH $22.5 \%(n=1,202$; [95\% CI 21.4-23.6]), and epAll-MIG + TTH 21.5\% $(n=1,150$; [95\% CI 20.4-22.6]).

Among women epAll-MIG was the most frequent $(34.4 \%, 32.8-36.1)$, whereas all other headache types were almost equally distributed. In men, unclassifiable headache was $30.6 \%$ ( $n=629$; [95\% CI 28.6-32.6]), followed by epAll-TTH 24.6\% ( $n=505$; [95\% CI 22.7-26.5]), epAllMIG $22.7 \%$ ( $n=466$; [95\% CI 20.9-24.5]) and epAllMIG + TTH $22.1 \% \quad(n=453 ; \quad[95 \%$ CI $20.3-23.9])$. Compared to men, women reported 2.4-fold increase of
epAll-MIG, 1.4 of epAll-TTH, and 1.5 of epAll-MIG + TTH.

In relation to age, Table 2 shows that in women epAllMIG peaks between 36 and 45 years and epAll-TTH and epAll-MIG + TTH between 18 and 35 years. In men, epAll-MIG peaks between 36 and 45 years, epAll-TTH show similar frequency in the age groups between 36 and 66 years and epAll-MIG + TTH show two peaks in the age groups 26 and 35 years and 46 and 55 years (Table 2).

Chronic headache

We identified 255 participants that reported headache on at least 15 days/month resulting in a prevalence of $2.6 \%$ (95\% CI 2.3-3) (Table 3). The prevalence was as follows: chronic MIG 42.4\% ( $n=108$; [95\% CI 36.3-48.4]), chronic MIG + TTH 29\% ( $n=74$; [95\% CI 23.5-34.6]), chronic TTH $19.6 \%(n=50$; [95\% CI 14.7-24.5]) and 


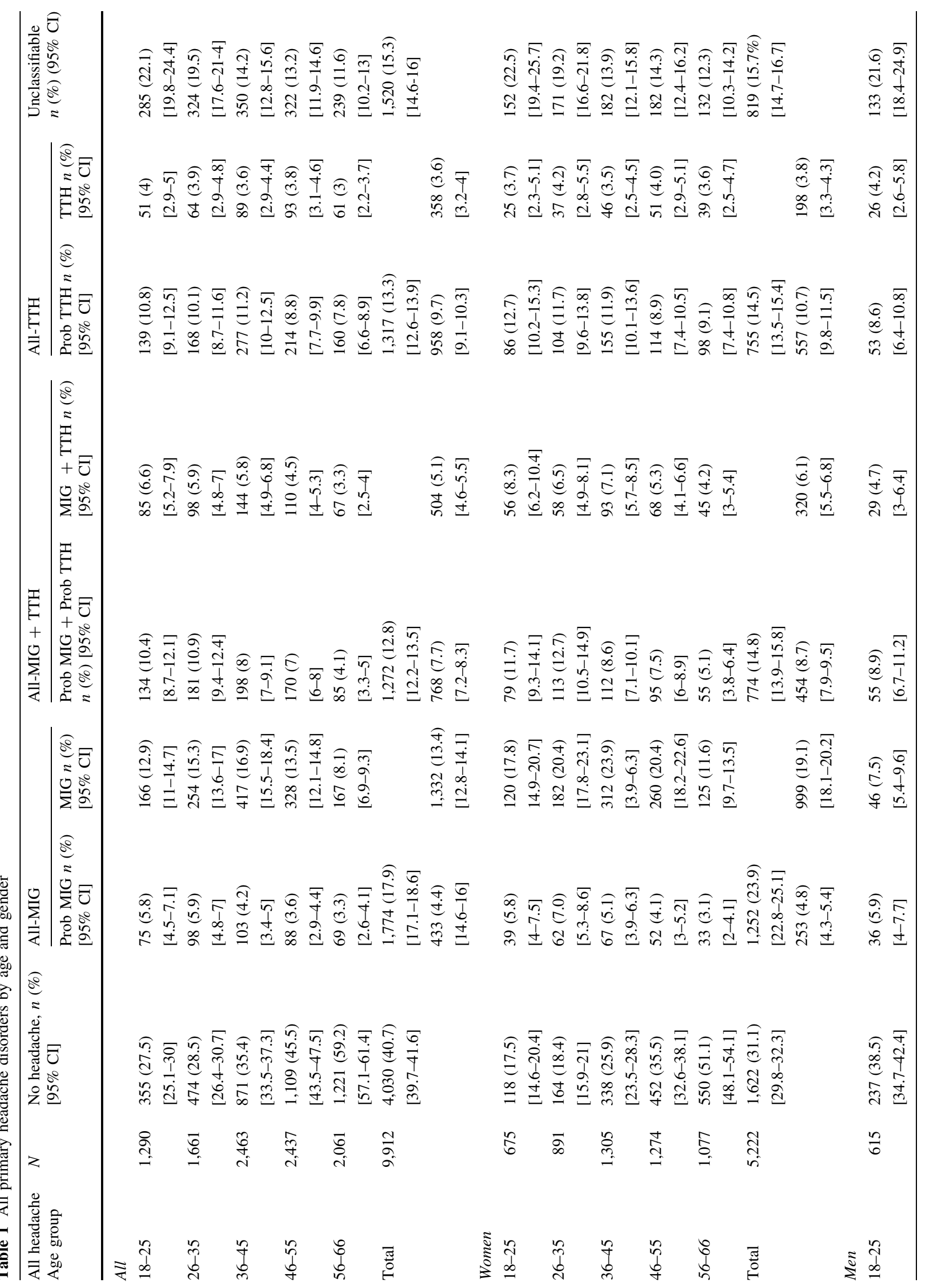




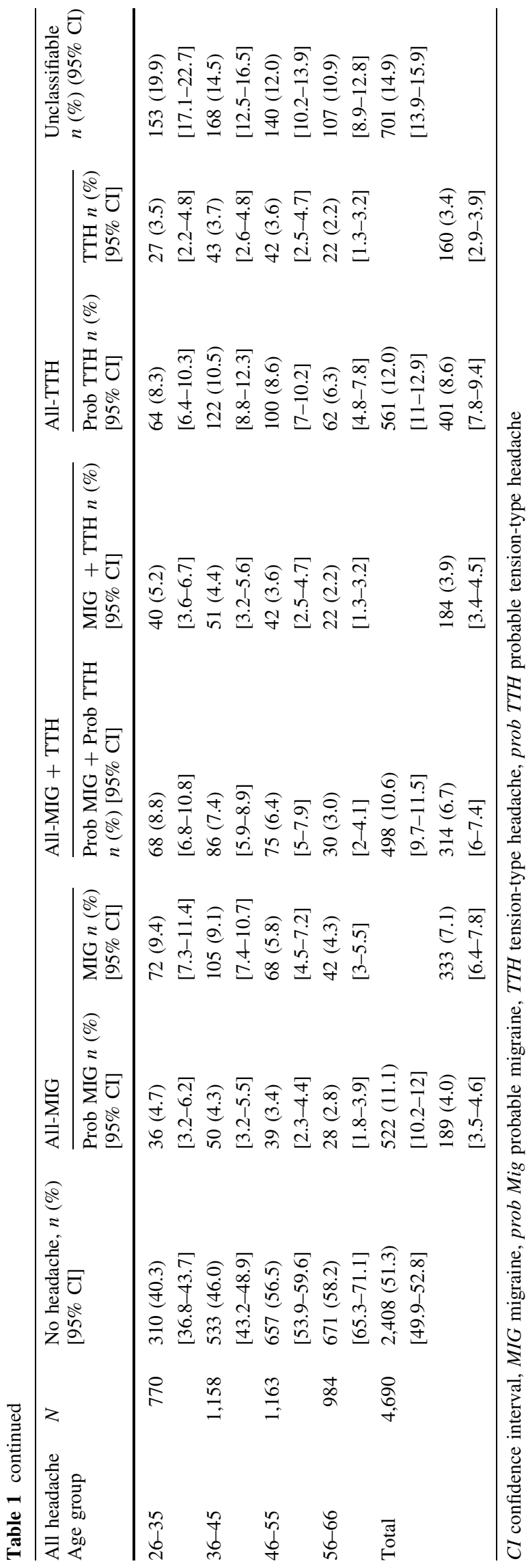

unclassifiable headache $9 \%(n=23$; [95\% CI 5.5-12.5]). Women were more frequently affected than men (65.1 vs. $34.9 \%$ ). Apparently chronic headache in women tends to become a bigger problem with increasing age (Table 3 ). In particular, chronic MIG and chronic MIG + TTH in women peak between 36 and 55 years, whereas chronic TTH peaks in the age group 56 and 66 years. In men chronic MIG peaks between 26 and 35 years, chronic MIG + TTH between 18 and 25 years and chronic TTH between 46 and 55 years.

\section{Discussion}

Population-based surveys assessing the prevalence of primary headache disorders in Germany are rare. The aim of our present work was to provide prevalence data of primary headache disorders including episodic and chronic headache forms in relation to sex and age in the general population in Germany. About 55\% of the participants reported any kind of headache within the last 12 months.

As far as migraine is concerned, our results are comparable to previous studies from other European countries and the USA [11-16]. The prevalence of migraine in Sweden was 13.2, $16.7 \%$ among women and 9.5\% among men [11], in England 18.3\% among women and 7.6\% among men [15] compared to the $13.4 \%$ of migraine prevalence in our study, $19.1 \%$ among women and $7.1 \%$ among men. The estimated prevalence of definite MIG and probable MIG in France and Austria was similar: $11.2 \%$ for definite MIG and $10.1 \%$ for probable MIG in France [13], $10.2 \%$ for definite MIG and $8.5 \%$ for probable MIG in Austria [12] compared to $13.4 \%$ definite MIG and $4.4 \%$ probable MIG in the present study. In the USA, the prevalence of MIG is about $17 \%$ in women and $6 \%$ in men [14, $16]$ which is comparable to our data as well $(19.1 \%$ in women and $7.1 \%$ in men).

Previous data on the prevalence of TTH are more heterogeneous. In Germany, the lifetime prevalence of TTH was reported to be $38.5 \%$ [6]. The 1-year prevalence in Croatia was $20.7 \%$ [17]. In Denmark, the 1-year prevalence of TTH in men was found to be 63 and $86 \%$ in women [18]. Several reasons may lead to this wide variation of estimated prevalence in TTH. For example, questionnaires may differ in their sensitivity to identify cases where respondents consider their symptoms trivial. The estimated 1-year prevalence of episodic TTH in our survey is comparable to estimates in Croatia [17] but is lower than previous estimates in Germany [6], in Georgia [10] and in Denmark [18].

We found 1,392 subjects with a headache frequency $<15$ days/month but with missing data to allow for further headache classification. Trigeminal autonomic cephalalgias 
Table 2 Episodic primary headache disorder
$C I$ confidence interval,

epAllMIG episodic all migraine, epAllTTH episodic all tensiontype headache, epUnclassifiable episodic unclassifiable, epAllMIG $+T T H$ episodic all migraine + tension-type headache, epHeadache episodic headache

\begin{tabular}{|c|c|c|c|c|c|}
\hline $\begin{array}{l}\text { epHeadache } \\
\text { age group }\end{array}$ & $N$ & $\begin{array}{l}\text { epAllMIG } \\
n(\%) \\
{[95 \% \mathrm{CI}]}\end{array}$ & $\begin{array}{l}\text { epAllMIG }+ \text { TTH } \\
n(\%) \\
{[95 \% \mathrm{CI}]}\end{array}$ & $\begin{array}{l}\text { epAllTTH } \\
n(\%) \\
{[95 \% \mathrm{CI}]}\end{array}$ & $\begin{array}{l}\text { epUnclassifiable } \\
n(\%) \\
{[95 \% \mathrm{CI}]}\end{array}$ \\
\hline \multicolumn{6}{|l|}{ All } \\
\hline $18-25$ & 854 & $\begin{array}{l}221(25.9) \\
{[22.9-28.8]}\end{array}$ & $\begin{array}{l}194(22.7) \\
{[19.9-25.5]}\end{array}$ & $\begin{array}{l}177(20.7) \\
{[18-23.4]}\end{array}$ & $\begin{array}{l}262(30.7) \\
{[27.6-33.8]}\end{array}$ \\
\hline $26-35$ & 1,116 & $\begin{array}{l}328(29.4) \\
{[26.7-32.1]}\end{array}$ & $\begin{array}{l}262(23.5) \\
{[21-26]}\end{array}$ & $\begin{array}{l}218(19.5) \\
{[17.2-21.9]}\end{array}$ & $\begin{array}{l}308(27.6) \\
{[25-30.2]}\end{array}$ \\
\hline $36-45$ & 1,482 & $\begin{array}{l}498(33.6) \\
{[31.2-36]}\end{array}$ & $\begin{array}{l}318(21.5) \\
{[19.4-23.6]}\end{array}$ & $\begin{array}{l}344(23.2) \\
{[21.1-25.4]}\end{array}$ & $\begin{array}{l}322(21.7) \\
{[19.6-23.8]}\end{array}$ \\
\hline $46-55$ & 1,190 & $\begin{array}{l}367(30.8) \\
{[28.2-33.5]}\end{array}$ & $\begin{array}{l}249(20.9) \\
{[18.6-23.2]}\end{array}$ & $\begin{array}{l}279(23.4) \\
{[21-25.9]}\end{array}$ & $\begin{array}{l}295(24.8) \\
{[22.3-27.2]}\end{array}$ \\
\hline $56-66$ & 707 & $\begin{array}{l}187(26.4) \\
{[23.2-29.7]}\end{array}$ & $\begin{array}{l}127(18) \\
{[15.1-20.8]}\end{array}$ & $\begin{array}{l}184(26) \\
{[22.8-29.3]}\end{array}$ & $\begin{array}{l}209(29.6) \\
{[26.2-32.9]}\end{array}$ \\
\hline Total & 5,349 & $\begin{array}{l}1,601(29.9) \\
{[28.7-31.2]}\end{array}$ & $\begin{array}{l}1,150(21.5) \\
{[20.4-22.6]}\end{array}$ & $\begin{array}{l}1,202(22.5) \\
{[21.4-23.6]}\end{array}$ & $\begin{array}{l}1,396(26.1) \\
{[24.9-27.3]}\end{array}$ \\
\hline \multicolumn{6}{|l|}{ Women } \\
\hline $18-25$ & 507 & $\begin{array}{l}145(28.6) \\
{[24.7-32.5]}\end{array}$ & $\begin{array}{l}119(23.5) \\
{[19.8-27.2]}\end{array}$ & $\begin{array}{l}102(20.1) \\
{[16.6-23.6]}\end{array}$ & $\begin{array}{l}141(27.8) \\
{[23.9-31.7]}\end{array}$ \\
\hline $26-35$ & 685 & $\begin{array}{l}229(33.4) \\
{[29.9-37]}\end{array}$ & $\begin{array}{l}158(23.1) \\
{[19.9-26.2]}\end{array}$ & $\begin{array}{l}134(19.6) \\
{[16.6-22.5]}\end{array}$ & $\begin{array}{l}164(23.9) \\
{[20.8-27.4]}\end{array}$ \\
\hline $36-45$ & 904 & $\begin{array}{l}353(39) \\
{[35.9-42.2]}\end{array}$ & $\begin{array}{l}192(21.2) \\
{[18.6-23.9]}\end{array}$ & $\begin{array}{l}189(20.9) \\
{[18.3-23.6]}\end{array}$ & $\begin{array}{l}170(18.8) \\
{[16.3-21.4]}\end{array}$ \\
\hline $46-55$ & 747 & $\begin{array}{l}274(36.7) \\
{[33.2-40.1]}\end{array}$ & $\begin{array}{l}144(19.3) \\
{[16.5-22.1]}\end{array}$ & $\begin{array}{l}156(20.9) \\
{[18-23.8]}\end{array}$ & $\begin{array}{l}173(23.2) \\
{[20.1-26.2]}\end{array}$ \\
\hline $56-66$ & 453 & $\begin{array}{l}134(29.6) \\
{[24.4-33.8]}\end{array}$ & $\begin{array}{l}84(18.5) \\
{[15-22.1]}\end{array}$ & $\begin{array}{l}116(25.6) \\
{[21.6-29.6]}\end{array}$ & $\begin{array}{l}119(26.3) \\
{[22.2-30.3]}\end{array}$ \\
\hline Total & 3,296 & $\begin{array}{l}1,135(34.4) \\
{[32.8-36.1]}\end{array}$ & $\begin{array}{l}697(21.1) \\
{[19.8-22.5]}\end{array}$ & $\begin{array}{l}697(21.1) \\
{[19.8-22.5]}\end{array}$ & $\begin{array}{l}767(23.3) \\
{[21.8-24.7]}\end{array}$ \\
\hline \multicolumn{6}{|l|}{ Men } \\
\hline $18-25$ & 347 & $\begin{array}{l}76(21.9) \\
{[17.6-26.3]}\end{array}$ & $\begin{array}{l}75(21.6) \\
{[17.3-25.9]}\end{array}$ & $\begin{array}{l}75(21.6) \\
{[17.3-25.9]}\end{array}$ & $\begin{array}{l}121(34.9) \\
{[29.9-39.9]}\end{array}$ \\
\hline $26-35$ & 431 & $\begin{array}{l}99(23) \\
{[19-26.9]}\end{array}$ & $\begin{array}{l}104(24.1) \\
{[20.1-28.2]}\end{array}$ & $\begin{array}{l}84(19.5) \\
{[15.8-23.2]}\end{array}$ & $\begin{array}{l}144(33.4) \\
{[29-37.9]}\end{array}$ \\
\hline $36-45$ & 578 & $\begin{array}{l}145(25.1) \\
{[21.6-28.6]}\end{array}$ & $\begin{array}{l}126(21.8) \\
{[18.4-25.2]}\end{array}$ & $\begin{array}{l}155(26.8) \\
{[23.2-30.4]}\end{array}$ & $\begin{array}{l}152(26.3) \\
{[22.7-29.9]}\end{array}$ \\
\hline $46-55$ & 443 & $\begin{array}{l}93(21) \\
{[17.2-24.8]}\end{array}$ & $\begin{array}{l}105(23.7) \\
{[19.7-27.7]}\end{array}$ & $\begin{array}{l}123(27.8) \\
{[23.6-31.9]}\end{array}$ & $\begin{array}{l}122(27.5) \\
{[23.4-31.7]}\end{array}$ \\
\hline $56-66$ & 254 & $\begin{array}{l}53(20.9) \\
{[15.9-25.9]}\end{array}$ & $\begin{array}{l}43(16.9) \\
{[12.3-21.5]}\end{array}$ & $\begin{array}{l}68(26.8) \\
{[21.3-32.2]}\end{array}$ & $\begin{array}{l}90(35.4) \\
{[29.6-41.3]}\end{array}$ \\
\hline Total & 2,053 & $\begin{array}{l}466(22.7) \\
{[20.9-24.5]}\end{array}$ & $\begin{array}{l}453(22.1) \\
{[20.3-23.9]}\end{array}$ & $\begin{array}{l}505(24.6) \\
{[22.7-26.5]}\end{array}$ & $\begin{array}{l}629(30.6) \\
{[28.6-32.6]}\end{array}$ \\
\hline
\end{tabular}

(TAC) and other primary headache disorders are unlikely to be detected in a population-based setting since the prevalence of these headache syndromes is rather low. Patients with TACs might be easily misclassified as either MIG or TTH leading to diverse results in either direction dependent on the design and focus of the respective questionnaire. As migraine is diagnosed essentially on the presence of specific features, and TTH by the absence of those same features, we think that these cases were most probably classified as TTH rather than migraine by our questionnaire.

In our population, the overall 1-year prevalence of chronic headache was $2.6 \%$. These results are in line with studies from Western Europe and the USA [19-21]. In Western Europe, chronic headache was reported to be $4.7 \%$ in participants aged over 14 years [19] out of which 
Table 3 Chronic headache

\begin{tabular}{|c|c|c|c|c|c|c|}
\hline & groups & & {$[95 \% \mathrm{CI}]$} & {$[95 \% \mathrm{CI}]$} & {$[95 \% \mathrm{CI}]$} & {$[95 \% \mathrm{CI}]$} \\
\hline & All & & & & & \\
\hline & $18-25$ & 36 & $13(36.1)$ & $13(36.1)$ & $5(13.9)$ & $5(13.9)$ \\
\hline & & & [20.4-51.8] & [20.4-51.8] & {$[2.6-25.2]$} & [2.6-25.2] \\
\hline & $26-35$ & 27 & $12(44.4)$ & $9(33.3)$ & $4(14.8)$ & $2(7.4)$ \\
\hline & & & [25.7-63.2] & {$[15.6-51.1]$} & [1.4-28.2] & {$[0-17.3]$} \\
\hline & $36-45$ & 44 & $19(43.2)$ & $13(29.5)$ & $8(18.2)$ & $4(9.1)$ \\
\hline & & & [28.6-57.8] & {$[16.1-43]$} & [6.8-29.6] & {$[0.6-17.6]$} \\
\hline & $46-55$ & 68 & $35(51.5)$ & $29(42.6)$ & $10(14.7)$ & $3(4.4)$ \\
\hline & & & [39.6-63.4] & {$[30.9-54.4]$} & {$[6.3-23.1]$} & [0-9.3] \\
\hline & $56-66$ & 80 & $29(36.3)$ & $19(23.7)$ & $23(28.8)$ & $9(11.3)$ \\
\hline & & & {$[25.7-46.8]$} & [14.4-33.1] & [18.8-38.7] & [4.3-18.2] \\
\hline & Total & 255 & $108(42.4)$ & $74(29)$ & $50(19.6)$ & $23(9)$ \\
\hline & & & [36.3-48.4] & [23.5-34.6] & [14.7-24.5] & {$[5.5-12.5]$} \\
\hline & Women & & & & & \\
\hline & $18-25$ & 30 & $12(40)$ & $10(33.3)$ & $4(13.3)$ & $4(13.3)$ \\
\hline & & & {$[22.5-57.5]$} & {$[16.5-50.2]$} & {$[1.2-25.5]$} & {$[1.2-25.5]$} \\
\hline & $26-35$ & 20 & $8(40)$ & $8(40)$ & $3(15)$ & $1(5)$ \\
\hline & & & [18.5-61.5] & [18.5-61.5] & {$[0-30.7]$} & {$[0-14.6]$} \\
\hline & $36-45$ & 26 & $14(53.8)$ & $8(30.8)$ & $3(11.5)$ & $1(3.8)$ \\
\hline & & & {$[34.7-73]$} & {$[13-48.5]$} & {$[0-23.8]$} & {$[0-11.2]$} \\
\hline & $46-55$ & 46 & $28(60.9)$ & $16(34.8)$ & $1(2.2)$ & $1(2.2)$ \\
\hline & & & [46.8-75] & [21-48.6] & {$[0-6.4]$} & [0-6.4] \\
\hline & $56-66$ & 44 & 17 (38.6) & $11(25)$ & $13(29.5)$ & $3(6.8)$ \\
\hline & & & [24.3-53] & [12.2-37.8] & [16.1-43] & {$[0-14.3]$} \\
\hline & Total & 166 & 79 (47.6) & 53 (31.9) & $24(14.5)$ & $10(6)$ \\
\hline & & & {$[40-55.2]$} & [24.8-39] & [9.1-19.8] & [2.4-9.6] \\
\hline & Men & & & & & \\
\hline & $18-25$ & 6 & $1(16.7)$ & $3(50)$ & $1(16.7)$ & $1(16.7)$ \\
\hline & & & {$[0-46.5]$} & [10-90] & {$[0-46.5]$} & {$[0-46.5]$} \\
\hline & $26-35$ & 7 & $4(57.1)$ & $1(14.3)$ & $1(14.3)$ & $1(14.3)$ \\
\hline & & & [20.5-93.8] & [0-40.2] & {$[0-40.2]$} & {$[0-40.2]$} \\
\hline & $36-45$ & 18 & $5(27.8)$ & $5(27.8)$ & $5(27.8)$ & $3(16.7)$ \\
\hline & & & [7.1-48.5] & [7.1-48.5] & [7.1-48.5] & [0-33.9] \\
\hline & $46-55$ & 22 & 7 (31.8) & $4(18.2)$ & $9(40.9)$ & $2(9.1)$ \\
\hline & & & [12.4-51.3] & {$[2.1-34.3]$} & [20.4-61.5] & [0-21.1] \\
\hline $\mathrm{CI}$ confidence interval, $\mathrm{CH}$ & $56-66$ & 36 & $12(33.3)$ & $8(22.2)$ & $10(27.8)$ & $6(16.7)$ \\
\hline chronic headache, $c M I G$ chronic & & & {$[17.9-48.7]$} & {$[8.6-35.8]$} & {$[13.2-42.4]$} & {$[4.5-28.8]$} \\
\hline migraine, $c T T H$ chronic tension- & Total & 89 & $29(32.6)$ & $21(23.6)$ & $26(29.2)$ & $13(14.6)$ \\
\hline $\begin{array}{l}\text { type headache, cUnclassifiable } \\
\text { chronic unclassifiable }\end{array}$ & & & {$[22.9-42.3]$} & {$[14.8-32.4]$} & [19.8-38.7] & [7.3-21.9] \\
\hline
\end{tabular}

chronic MIG was found to be $2.4 \%$ and chronic TTH $2.2 \%$. In a large population-based survey from France, the overall prevalence of chronic headache in subjects aged over 15 years was $2.9 \%$ out of which two-thirds had chronic migraine [20]. In the USA, the overall prevalence of chronic headache between 18 and 65 years was $4.1 \%$ (female to male ratio: 1.8:1). Interestingly, the subjects in this study more often reported chronic TTH $(>50 \%)$ than chronic MIG (female: 33\%, male 25\%) [21]. Chronic headache that could not be clearly identified was found in $15 \%$ in women and $19 \%$ in men [21]. Subjects that reported headache on 15 days/month or more in our study, chronic MIG was more frequent $(42.4,47.6 \%$ in women and $32.6 \%$ in men) than chronic TTH $(19.6,14.5 \%$ in women and $29.2 \%$ in men). The women to men ratio was $2.7: 1$ for chronic MIG and 0.9:1 for chronic TTH.

The strengths of our study are the large population-based sample recruited in 3 different regions of Germany, the high 
response rate of $55 \%$, and the use of a validated questionnaire. A false negative rate around $15 \%$ is compatible with the sensitivities of our questionnaire for MIG (0.73) and TTH $(0.85)[4,9]$.

Some limitations of our study need to be addressed. Although the response of our survey was satisfactory, possible selection bias might have occurred. For example, very old and very young people more often refuse to take part in surveys, and persons that suffer from headache possibly more often participate in survey seemingly affecting them, than persons not suffering from headache at all. However, these limitations pose a challenge that all questionnaire-based surveys have to face.

In conclusion, we provided comprehensive and detailed prevalence estimates of primary headache disorders in the general population in Germany. These data are valuable in emphasizing the importance of episodic and chronic headache in regard to health economics and the burden of disease within a population. The next steps will have to include the in-depth investigation of associated risk factors that may be associated with episodic headache and lead to chronic headache. There is much more to learn about the role of possible influencing factors like socioeconomic status, smoking, or obesity on headache prevalence in the general population.

Acknowledgments Supported by the Federal Ministry of Education and Research (BMBF), Germany.

Open Access This article is distributed under the terms of the Creative Commons Attribution License which permits any use, distribution, and reproduction in any medium, provided the original author(s) and the source are credited.

\section{References}

1. Stovner L, Hagen K, Jensen R, Katsarava Z, Lipton R, Scher A, Steiner T, Zwart JA (2007) The global burden of headache: a documentation of headache prevalence and disability worldwide. Cephalalgia 27:193-210

2. WHO (2001) The World Health Report, vol. 2. WHO, Geneva

3. Katsarava Z, Kukava M, Mirvelashvili E, Tavadze A, Dzagnidze A, Djibuti M, Steiner TJ (2007) A pilot methodological validation study for a population-based survey of the prevalences of migraine, tension-type headache and chronic daily headache in the country of Georgia. J Headache Pain 8:77-82

4. Fritsche G, Hueppe M, Kukava M, Dzagnidze A, Schuerks M, Yoon MS, Diener HC, Katsarava Z (2007) Validation of a German language questionnaire for screening for migraine, tension-type headache, and trigeminal autonomic cephalgias. Headache 47:546-551

5. Steiner T, World Headache Alliance (2004) Lifting the burden: the global campaign against headache. Lancet Neurol 3:204-205

6. Gobel H, Petersen-Braun M, Soyka D (1994) The epidemiology of headache in Germany: a nationwide survey of a representative sample on the basis of the headache classification of the International Headache Society. Cephalalgia 14:97-106

7. Hagen K, Zwart JA, Vatten L, Stovner LJ, Bovim G (2000) Prevalence of migraine and non-migrainous headache-headHUNT, a large population-based study. Cephalalgia 20:900-906

8. ICHD-2 (2004) The International Classification of Headache Disorders, 2nd edn. Cephalalgia 24:9-160

9. Yoon MS, Obermann M, Fritsche G, Slomke M, Dommes P, Schilf C, Diener HC, Katsarava Z (2008) Population-based validation of a German-language self-administered headache questionnaire. Cephalalgia 28:605-608

10. Katsarava Z, Dzagnidze A, Kukava M, Mirvelashvili E, Djibuti M, Janelidze M, Jensen R, Stovner LJ, Steiner TJ (2009) Primary headache disorders in the Republic of Georgia: prevalence and risk factors. Neurology 73:1796-1803

11. Dahlof C, Linde M (2001) One-year prevalence of migraine in Sweden: a population-based study in adults. Cephalalgia 21:664-671

12. Lampl C, Buzath A, Baumhackl U, Klingler D (2003) One-year prevalence of migraine in Austria: a nation-wide survey. Cephalalgia 23:280-286

13. Lanteri-Minet M, Valade D, Geraud G, Chautard MH, Lucas C (2005) Migraine and probable migraine-results of FRAMIG 3, a French nationwide survey carried out according to the 2004 IHS classification. Cephalalgia 25:1146-1158

14. Lipton RB, Scher AI, Kolodner K, Liberman J, Steiner TJ, Stewart WF (2002) Migraine in the United States: epidemiology and patterns of health care use. Neurology 58:885-894

15. Steiner TJ, Scher AI, Stewart WF, Kolodner K, Liberman J, Lipton RB (2003) The prevalence and disability burden of adult migraine in England and their relationships to age, gender and ethnicity. Cephalalgia 23:519-527

16. Stewart WF, Lipton RB, Celentano DD, Reed ML (1992) Prevalence of migraine headache in the United States. Relation to age, income, race, and other sociodemographic factors. JAMA 267: 64-69

17. Vukovic V, Plavec D, Pavelin S, Janculjak D, Ivankovic M, Demarin V (2010) Prevalence of migraine, probable migraine and tension-type headache in the Croatian population. Neuroepidemiology 35:59-65

18. Rasmussen BK, Jensen R, Schroll M, Olesen J (1991) Epidemiology of headache in a general population-a prevalence study. J Clin Epidemiol 44:1147-1157

19. Castillo J, Munoz P, Guitera V, Pascual J (1999) Epidemiology of chronic daily headache in the general population. Headache 39:190-196

20. Lanteri-Minet M, Auray JP, El Hasnaoui A, Dartigues JF, Duru G, Henry P, Lucas C, Pradalier A, Chazot G, Gaudin AF (2003) Prevalence and description of chronic daily headache in the general population in France. Pain 102:143-149

21. Scher AI, Stewart WF, Liberman J, Lipton RB (1998) Prevalence of frequent headache in a population sample. Headache 38: 497-506 